\title{
GC-MS Analysis of Bioactive Compounds and Host- toxicity Studies of Azolla caroliniana Symbiotic with the Cyanobacterium Anabaena azollae
}

\author{
Nabakishore Nayak, Rabindra Nath Padhy* \\ Central Research Laboratory, IMS and Sum Hospital, Siksha 'O’ Anusandhan University, Kalinga Nagar, Bhubaneswar 751003, Odisha, \\ INDIA.
}

\begin{abstract}
Objective: The present research work was conducted to do the gas chromatography and mass spectrometry (GC-MS) analysis of the water fern, Azolla caroliniana symbiotic with the cyanobacterium Anabaena azollae, along with in vitro host toxicity testing to check its toxicity level. Materials and methods: The GC-MS analysis of the methanol extract of $A$. caroliniana was carried out using a GC-MS instrument and in vitro host toxicity testing of $A$. caroliniana extract was carried out with cultured lymphocytes from human umbilical cord blood. Results: It was evident that only one phytochemical, 3-o-methyld-glucose with retention time $16.581 \mathrm{~min}$ and a peak area of $91.89 \%$ as the major phytochemical was present in methanolic extract of the fern, while the rest 7 of the total 8 chemicals namely (with peak area values), '2-butanone, 3-methoxy-3-methyl' $(0.865 \%)$, '2,2-dimethyl propionic acid, cyclopentyl ester' $(0.670 \%)$, 'butane, 1-bromo2-methyl' (0.398\%), '2-hexen-1-ol,2-ethyl' (0.269\%), '5-hydroxy-2,2-dimethyl hexan3-one' $(0.212 \%)$, 'phthalic acid, ethyl pentyl ester' $(0.21 \%)$, 'pentanoic acid, 2-methyl' $(0.182 \%)$, were present in minor quantities. Host toxicity testing was done with in vitro cultured lymphocytes from human umbilical cord blood. The LC $_{25}$ values were 870.96 and $691.83 \mathrm{mg} / \mathrm{L}$ with the trypan blue and acridine orange/ethidium bromide staining, respectively by methanolic extract of $A$. caroliniana in cellular toxicity experiments, against the minimum inhibitory concentration values of $300 \mathrm{mg} / \mathrm{L}$ extract. During the assessment of nuclear toxicity, no comet was found in the cells grown with 0 to 1000 $\mathrm{mg} / \mathrm{L}$ of the extract. Conclusion: The extract had neither cellular nor nuclear toxicity to cultured human lymphocytes.
\end{abstract}

Key words: Azolla caroliniana, Fern, Gc-Ms Analysis, 3-O-Methyl-D-Glucose, Host Toxicity Testing, In Vitro Cultured Lymphocytes.

\section{INTRODUCTION}

One among 7 species of Azolla (Salviniaceae), A. caroliniana Willdenow, the 'mosquito/ water fern', is a small fast-growing freefloating hydrophyte of idle tropical/ temperate fresh waters, worldwide. ${ }^{1}$ Azolla sp. is traditionally used as a bio-fertilizer in Asian rice farming by growing and mixing into rice-soil during puddling, as well as an animal feed mainly. ${ }^{2,3}$ Because of its symbiosis with the $\mathrm{N}_{2}$-fixing cyanobacterium, Anabaena azollae, it adds nitrogenous compounds to the growing environment and helps soil-conditioning. ${ }^{1-3}$
The wide use of Azolla sp. as cattle and poultry feed and limited use as human food, particularly seen in China is known. ${ }^{4}$ Its antioxidant capabilities were assessed with $A$. caroliniana, with several biochemical methods, with a record of its antibacterial capabilities in parallel, with 7 human pathogenic multidrug resistant (MDR) bacteria isolated from clinical samples. Surprisingly, antioxidant and antibacterial capabilities of the species were blithely confirmed, since both activities are of rare occurrence in a plant. Preliminary phytochemical analyses
Submission Date: 16-01-2017; Revision Date: 14-03-2017; Accepted Date: 18-03-2017

DOI: 10.5530/ijper.51.2s.46

Correspondence Dr. Rabindra N. Padhy, Central Research Laboratory, IMS and Sum Hospital, Siksha 'O' Anusandhan University, Kalinga Nagar, Bhubaneswar 751003, Odisha, INDIA. Phone No:- +919437134982 E-mail: rnpadhy54@gmail. com;

E mail: nkishorenayak@ yahoo.co.in

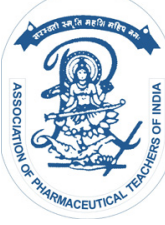

www.ijper.org 
of fern-extracts with solvents, chloroform, ethanol, methanol and $n$-hexane for the presence of alkaloids, anthraquinones, carbohydrates, flavonoids, glycosides, phenols, resin, saponins, steroids, tannins and terpenoids were recorded. ${ }^{5}$ Intuitively, there had been a logistic interest in detailing the phytochemical contents of biologically active extract of $A$. caroliniana, due to its dual beneficial medicinal role.

However, the first attempt on the phytochemical composition of the Indian species, $A$. filiculoides described the presence of C-glycosyl flavones. ${ }^{6}$ A comparative study of $A$. pinnata extracted with acetone, benzene, chloroform, water, ethanol and petroleum ether reported presence of phenols, tannins, flavonoids and saponins. ${ }^{7}$ A preliminary examination of the phytochemical profile of A. microphylla too indicated the presence of sterols, tannins, flavonoids and glycosides, moderately. ${ }^{8}$ Moreover, two flavonoids, rutin and quercetin having antioxidant activity were identified from another Indian species, A. microphylla. ${ }^{9}$ In the previous work on A. caroliniana it was found that methanol extract of plant had considerable amounts of phenolic compounds justifying its antioxidant capability; additionally, methanol, ethanol and chloroform extracts of $A$. caroliniana were recorded the presence of flavonoids, phenols, saponins and tannins. ${ }^{5}$ Methanolic extract of $A$. microphylla, was used for assessing antibacterial activity in vitro against with bacterium, Xanthomonas oryzae pathogenic on rice and bioactive compounds as a mixture of eicosenes and heptadecanes were reported with a GC-MS analysis of the ethyl acetate fraction. ${ }^{10}$

This study on gas chromatography and mass spectrometry (GC-MS) analysis of methanolic extract of A. microphylla was the continuation of the previous study on the antibacterial and antioxidant properties of the fern, ${ }^{5}$ for assessing its bioactive compounds in detail. In addition, host toxicity testing of the fern extract of with in vitro cultured lymphocytes from human umbilical cord blood was pursued, similar to the recently surging 'predictive toxicology' work, described on a chemical of environmental concern, ${ }^{11}$ since host toxicity testing is an essential corollary to such a scientific assertion of a nonconventional (but generally known as non-toxic) Indian plant species as a food-grade plant for man, in corroboration to the previous nutrition-level checking report ${ }^{12}$ and organoleptic work. ${ }^{5}$ Furthermore, testing of cellular and nuclear toxicity with a human cell line should be regarded as an attempt of revealing the consequence of exact mirror of untoward body events in any, from the use of Azolla as a food grade plant. Obviously, the use of whole animals is the most coveted method of host toxicity testing of any new chemical/food grade material, traditionally in pharmacology. Nevertheless, the later method is too under circumspection as the most dependable method, for the reason of the suppression of probable toxic events due to physiological homeostasis of live animals that might be of different in man, despite the fact that most conventional experimental animals are mammals. In the present study, the methanolic extract of $A$. caroliniana was analyzed by GC-MS study, and several bioactive compounds were identified. This work is anticipated that, $A$. carolinian could be recommended as supplementary food after conformation of its detailed chemical contents and absence of any toxic effects holistically to host, verified with a human cell culture line in vitro.

\section{MATERIALS AND METHODS}

\section{Collection and extract preparation}

Arolla caroliniana was collected from a local animal farm, where it was grown in a well illuminated cement tank. Fern-fronds were harvested and were shade dried. Methanolic extract was prepared by the cold extraction method from the dried mass, using a vacuum rotary evaporator for a semisolid mass as described. ${ }^{5}$ The extract was further stored in small vials in $10 \%$ dimethyl sulfoxide (DMSO), for a concentration of $100 \mathrm{mg} / \mathrm{mL}$.

\section{GC-MS analysis}

The GC-MS analysis of the methanol extract was carried out using an instrument equipped with a VF-5 ms fused-silica capillary column of $30 \mathrm{~m}$ length, $0.25 \mathrm{~mm}$ diameter, and $0.25 \mathrm{~mm}$ film thickness. An electron ionization system with ionization energy of $70 \mathrm{eV}$ was used as the detector. Helium gas $(99.99 \%)$ was used as the carrier gas at the constant flow-rate of $1.51 \mathrm{~mL} / \mathrm{min}$. The temperatures of the injector and mass transfer line were set at $200^{\circ} \mathrm{C}$ and $240^{\circ} \mathrm{C}$, respectively. The oven temperature was programmed from $70^{\circ} \mathrm{C}$ to $220^{\circ} \mathrm{C}$ at $10^{\circ} \mathrm{C} / \mathrm{min}$, held constant for $1 \mathrm{~min}$ and finally increased to $300^{\circ} \mathrm{C}$ at $10^{\circ} \mathrm{C} / \mathrm{min}$. Aliquots of $2 \mathrm{~mL}$ of the diluted samples were manually injected in the split-less mode with a split ratio of 1:40 and with a mass scan range of 50e600 AMU. The total running time of the GC-MS analysis was $60 \mathrm{~min} .{ }^{13}$

\section{Identification of compounds}

The phytochemical components of the biologically active methanolic extract was identified by comparing their fragmentation pattern of mass spectra and retention indices with those stored in the following databases: NIST08.LIB (Stein SE National Institute of Standards and Technology, Mass Spectral Database and Software. Version 3.02, NIST, Gaithersburg, MD, USA, 1990) and 
WILEY8.LIB ${ }^{14}$; and comparisons with other published work of mass spectra were done.

\section{Host toxicity study with human lymphocytes Isolation of lymphocytes}

Human umbilical cord blood (UCB) was collected in a sterile 15 or $50 \mathrm{~mL}$ size falcon tube (Tarson, Kolkata), with an aliquot of 100 or $250 \mu \mathrm{L} 1,000 \mathrm{IU}$ heparin (HiMedia, Mumbai), immediately after the delivery of an infant. And the blood sample (less than 15 to $50 \mathrm{~mL}$ ) was stored at $4^{\circ} \mathrm{C}$ till use; lymphocytes were isolated immediately or within at the best $24 \mathrm{~h}$ after the collection. For the isolation of lymphocytes, the collected UCB sample was diluted with an equal volume of phosphate buffered saline (PBS) solution. Further, the mixture was loaded carefully into a centrifuge tube for over-layering with lymphocyte separating medium (LSM, HiMedia), which was one-third the total volume of the mixture. The mixture was centrifuged at 1,800 rpm for $25 \mathrm{~min}$ at $22-24^{\circ} \mathrm{C}$, as a result four heavy to light layers, red blood cells (RBC), LSM, buffy coat and plasma were seen. The buffy coat layer with mononuclear cells was taken out carefully from the tube. To the separated cells of the buffy coat layer, after the addition of another aliquot of PBS for the 1:1 ratio, re-centrifugation at 2,000 rpm for 5 min was done. The pellet of lymphocytes was taken for culturing and cell counts were done using a haemocytometer. ${ }^{11}$

\section{Culture of lymphocyte}

After separation, UCB-derived lymphocytes were diluted to the density of $1 \times 10^{6}$ cells $/ \mathrm{mL}$ with a required volume of Dulbecco's modified Eagle's medium (DMEM-lowglucose, HiMedia), and were loaded into a 6-well culture plate (Tarson), which contained 15\% fetal bovine serum (FBS, Sigma), 1\% penicillin-streptomycin and 1\% sodium pyruvate, along with graded concentrations of A. caroliniana extract for growth. The volume of $2 \mathrm{~mL}$ in total was maintained in each well of the culture plate with the extract at different concentrations. The cells were incubated with different concentrations of A. caroliniana extract $(0,100,200,300,400,500,600$, $700,800,900$ and $1000 \mathrm{mg} / \mathrm{L}$ ) in an incubator at $37^{\circ} \mathrm{C}$ in $5 \%$ atmospheric $\mathrm{CO}_{2}$ concentration for $24 \mathrm{~h}$ for growth in vitro. ${ }^{11}$

\section{Monitoring cellular toxicity}

The viability of lymphocytes grown in the presence of the extract was assessed using two staining procedures, with trypan blue (TB) and acridine orange/ethidium bromide $(\mathrm{AO} / \mathrm{EB})$, using phase contrast microscope (Magnus) and a fluorescent, respectively.

\section{TB staining}

TB solution was prepared in PBS at the concentration of $0.4 \%$. For the study of cell viability, to the in vitro grown mass of lymphocytes, TB solution was added at the 1:1 ratio. Then the mixture was kept in an incubator for 2 min at $37^{\circ} \mathrm{C}$; cells in triplicates were observed under a phase-contrast microscope (Magnus) at 400x magnification. The live cells remained unstained whereas; the nuclei of dead cells were blue in appearance, as TB is a membrane permeable dye that enters dead cells and stains the nuclei blue.

\section{AO/EB staining}

The AO/EB solution was prepared in PBS at the concentration of $100 \mu \mathrm{g} / \mathrm{mL}$. To the lymphocytes grown at different concentrations of $A$. caroliniana extract, the $\mathrm{AO} / \mathrm{EB}$ solution was added at $4 \mu \mathrm{L}$ to $96 \mu \mathrm{L}$ lymphocytes. When observed under the fluorescent microscope (Magnus at 400X), green colour indicated live cells, whereas cells with orange and red colour were apoptotic and necrotic cells, respectively. Lethal percent values were transformed to probit values (Finney's method), which were plotted against corresponding $\log _{10}$ values of A. caroliniana extract concentrations, as exemplified before. ${ }^{11}$ Probits of observed lethality percentage values are from statistical tables of probit transformation, as described recently. ${ }^{11}$

\section{Comet assay}

Single cell gel electrophoresis was carried out to study nuclear/ DNA damage of the lymphocytes grown with graded concentrations of $A$. caroliniana extract. Cultured cells were harvested and used in the alkaline comet assay technique. After coating slides with 1\% agarose were air dried. Cultured lymphocytes individually from each A. caroliniana extract concentration were centrifuged and pellets were washed with PBS; and the washed cells were mixed with three times the cell volume with the low melting point agarose (LMPA) 1\% in sol state. The mixture of cells and LMPA sol was placed over the agarose coated slide that was kept at $4^{\circ} \mathrm{C}$ for $10 \mathrm{~min}$ for it to get dried. The slides were further treated with $1 \%$ Triton X 100, 10\% DMSO, individually, and were placed in the lysing solution of the mixture of $100 \mathrm{mM}$ $\mathrm{Na}_{2}$ EDTA, $10 \mathrm{mM}$ Tris, $2.5 \mathrm{mM} \mathrm{NaCl}(\mathrm{pH}, 10)$, at $4^{\circ} \mathrm{C}$ for $1 \mathrm{~h}$. The slides were subsequently removed and placed in the electrophoretic buffer consisting of $1 \mathrm{mM}$ $\mathrm{Na}_{2}$ EDTA and $300 \mathrm{mM} \mathrm{NaOH}(\mathrm{pH}$ 13) for $30 \mathrm{~min}$. The slides were transferred to a horizontal gel electrophoretic chamber with electrophoretic buffer. Electrophoresis was carried out at $1.0 \mathrm{~V} / \mathrm{cm}$ for $30 \mathrm{~min}$. After the electrophoresis, the slides were placed in the 
neutralizing solution ( $0.4 \mathrm{M}$ Tris $\mathrm{HCl}, \mathrm{pH} 7.5)$ for $5 \mathrm{~min}$. The slides were stained with an aliquot of $40 \mu \mathrm{L}$ of $10 \mu \mathrm{g} / \mathrm{mL}$ ethidium bromide solution. ${ }^{15}$ The slides were observed under the fluorescence microscope at $400 \mathrm{X} .{ }^{11}$

\section{RESULTS}

\section{GC-MS analysis of $\boldsymbol{A}$. caroliniana}

From the GC-MS analysis of the methanolic extract, the presence of 8 phytocompounds was evident in the chromatogram (Figure 1). Chemical profiles of the identified compounds were ascertained together with their retention time (RT), percentage of peak area, molecular formula, molecular weight and chemical structure (Table 1). Studies on the phytochemicals of A. caroliniana by the GC-MS analysis clearly showed the presence of 8 compounds, as follows with RT as min in the order, 15.551, 16.581, 18.022, 18.212, 18.392, 18.582, 19.002 and $20.762 \mathrm{~min}$, respectively: A, phthalic acid, ethyl pentyl ester (0.21\%); B, 3-o-methyl-d-glucose (OMG) (91.89\%); C, 2-butanone, 3-methoxy-3-methyl (0.865\%); D, 2,2-dimethylpropionic acid, cyclopentyl ester $(0.670 \%)$; E, 2-Hexen-1-ol, 2-ethyl (0.269\%);

\begin{tabular}{|c|c|c|c|c|c|c|c|}
\hline Peak & RT & Area & Area \% & Name of compound & MF & MW & Molecular structure \\
\hline A & 15.551 & $58,207.1$ & 0.21 & Phthalic acid, ethyl pentyl ester & $\mathrm{C}_{15} \mathrm{H}_{20} \mathrm{O}_{4}$ & 264 & \\
\hline B & 16.581 & $25,191,662$ & 91.89 & 3-O-Methyl-d-glucose & $\mathrm{C}_{7} \mathrm{H}_{14} \mathrm{O}_{6}$ & 194 & \\
\hline c & 18.022 & $237,223.1$ & 0.865 & 2-Butanone, 3-methoxy-3-methyl & $\mathrm{C}_{6} \mathrm{H}_{12} \mathrm{O}_{2}$ & 116 & \\
\hline $\mathrm{D}$ & 18.212 & $183,612.5$ & 0.670 & $\begin{array}{l}\text { 2,2-Dimethyl propionic acid, } \\
\text { cyclopentyl ester }\end{array}$ & $\mathrm{C}_{10} \mathrm{H}_{18} \mathrm{O}_{2}$ & 170 & \\
\hline $\mathrm{E}$ & 18.392 & $73,650.7$ & 0.269 & 2-Hexen-1-ol, 2-ethyl & $\mathrm{C}_{8} \mathrm{H}_{16} \mathrm{O}$ & 128 & \\
\hline $\mathrm{F}$ & 18.582 & $58,129.3$ & 0.212 & 5-Hydroxy-2,2-dimethyl hexan-3-one & $\mathrm{C}_{8} \mathrm{H}_{16} \mathrm{O}_{2}$ & 144 & \\
\hline G & 19.002 & $49,967.7$ & 0.182 & Pentanoic acid, 2-methyl & $\mathrm{C}_{6} \mathrm{H}_{12} \mathrm{O}_{6}$ & 116 & \\
\hline $\mathrm{H}$ & 20.762 & $109,082.3$ & 0.398 & Butane, 1-bromo-2-methyl & $\mathrm{C}_{5} \mathrm{H}_{11} \mathrm{Br}$ & 150 & \\
\hline
\end{tabular}

Remark: $\mathrm{RT}$ = retention time (min), MF = molecular formula, $\mathrm{MW}=$ molecular weight. 


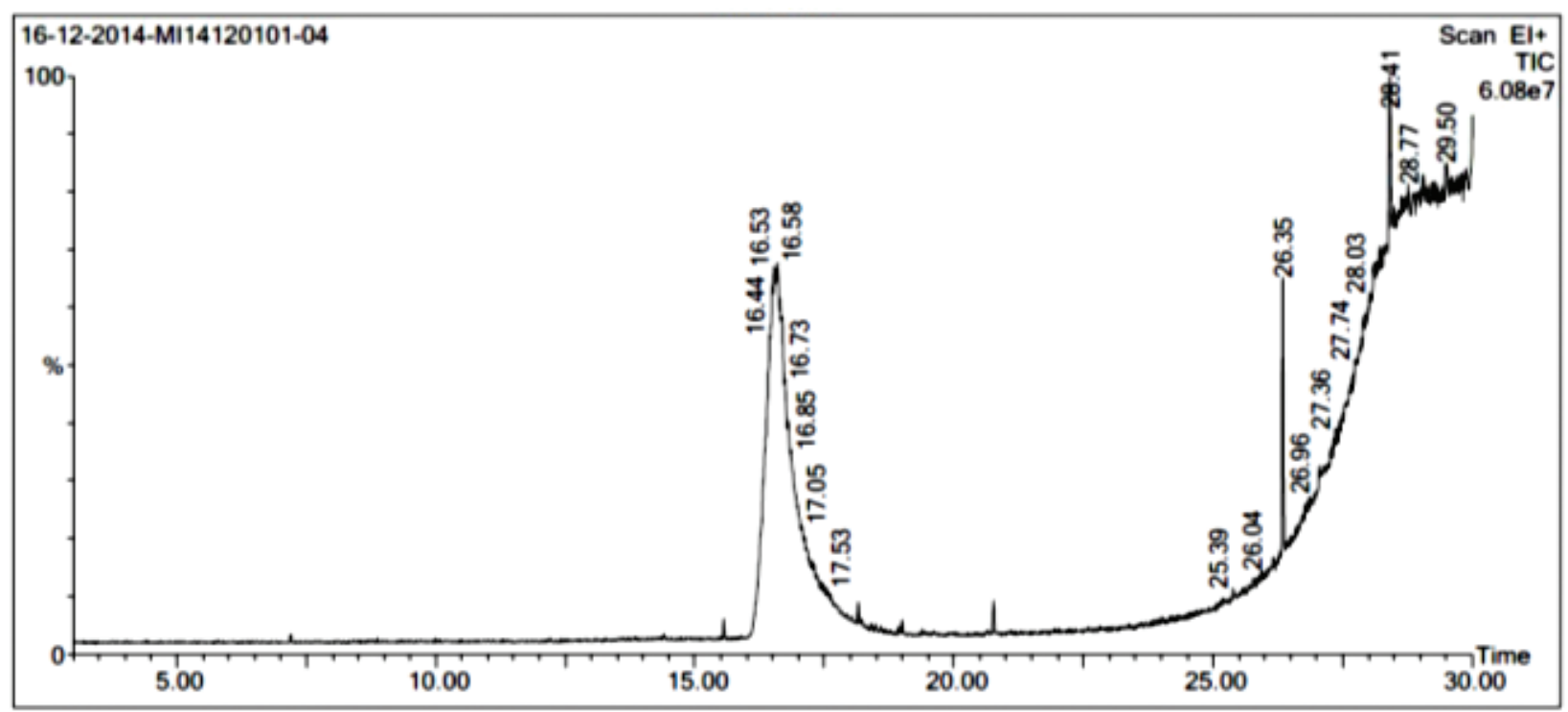

Figure 1: Gas chromatography-mass spectrometry chromatogram of methanolic extract of $A$. caroliniana.

\begin{tabular}{|c|c|c|c|c|c|}
\hline $\begin{array}{l}\text { Concentrations of } \\
\text { A. caroliniana } \\
\text { extract (mg/l) }\end{array}$ & $\begin{array}{c}\log _{10} \\
\text { Concentrations }\end{array}$ & $\begin{array}{c}\text { Lethal percent } \\
\text { value with } A O / E B \\
\text { staining }\end{array}$ & $\begin{array}{c}\text { Probit values } \\
\text { with } A O / E B \\
\text { staining }\end{array}$ & $\begin{array}{l}\text { Lethal percent value } \\
\text { with TB staining }\end{array}$ & $\begin{array}{l}\text { Probit values with } \\
\text { TB staining }\end{array}$ \\
\hline 0 & 0 & 0 & 0 & 0 & 0 \\
\hline 100 & 2.0 & 0 & 0 & 0 & 0 \\
\hline 200 & 2.301 & 0 & 0 & 0 & 0 \\
\hline 300 & 2.477 & $4.6 \pm 2.08$ & 3.32 & $5.0 \pm 2.64$ & 3.35 \\
\hline 400 & 2.602 & $10.6 \pm 1.52$ & 3.75 & $8.6 \pm 2.51$ & 3.63 \\
\hline 500 & 2.698 & $10.6 \pm 1.52$ & 3.75 & $10.6 \pm 1.52$ & 3.75 \\
\hline 600 & 2.778 & $21.0 \pm 2.64$ & 4.20 & $20.0 \pm 2.64$ & 4.16 \\
\hline 700 & 2.845 & $24.0 \pm 1.00$ & 4.30 & $10.6 \pm 1.52$ & 3.75 \\
\hline 800 & 2.903 & $21.0 \pm 2.64$ & 4.20 & $23.6 \pm 2.08$ & 4.28 \\
\hline 900 & 2.954 & $30.6 \pm 3.51$ & 4.50 & $24.0 \pm 1.00$ & 4.29 \\
\hline 1000 & 3.0 & $33.6 \pm 3.57$ & 4.57 & $29.6 \pm 2.08$ & 4.46 \\
\hline
\end{tabular}

Remark: $\mathrm{AO} / \mathrm{EB}=$ Acridine orange/ethidium bromide, $\mathrm{TB}=$ Trypan blue, $\mathrm{DMEM}=$ Dulbecco's modified Eagle's medium

F, 5-hydroxy-2,2-dimethylhexan-3-one (0.212\%); G, pentanoic acid, 2-methyl $(0.182 \%)$; H, butane, 1-bromo2-methyl $(0.398 \%)$ (Table 1, Figure $2 \mathrm{~A}$ to $2 \mathrm{H}$ ). The OMG (Figure 2B) has synonyms, 2,4,5,6-tetrahydroxy3-methoxy-hexanal and methyl glucose (https://www. wikigenes. org/e/chem/e/ 298225.html). However, the rest 7 chemicals, marked as, A, C. D, E, F, G and H (Figure 2) were in minor quantities.

\section{Assessments of A. caroliniana extract host toxicity}

Lethal percent values recorded from data sets of cellular toxicity tests with $\mathrm{AO} / \mathrm{EB}$ and $\mathrm{TB}$ staining methods of cultured lymphocytes were used along with $\log _{10}$ concentrations of the $A$. caroliniana extract to construct respective probit plots, which were used for extrapolation to compute individual $\mathrm{LC}_{25}$ values.

TB staining indicated that after growing lymphocytes with graded concentrations of $A$. caroliniana extract at 0 to $1000 \mathrm{mg} / \mathrm{L}$, the minimum inhibitory concentration (MIC) value after TB staining was recorded as $300 \mathrm{mg} / \mathrm{L}$ extract. From the probit plot, it was ascertained that for the value of $\mathrm{LC}_{25}$ (probit value 4.3255), the corresponding $\log _{10}$ concentration value was 2.84. Antilog value of 
A
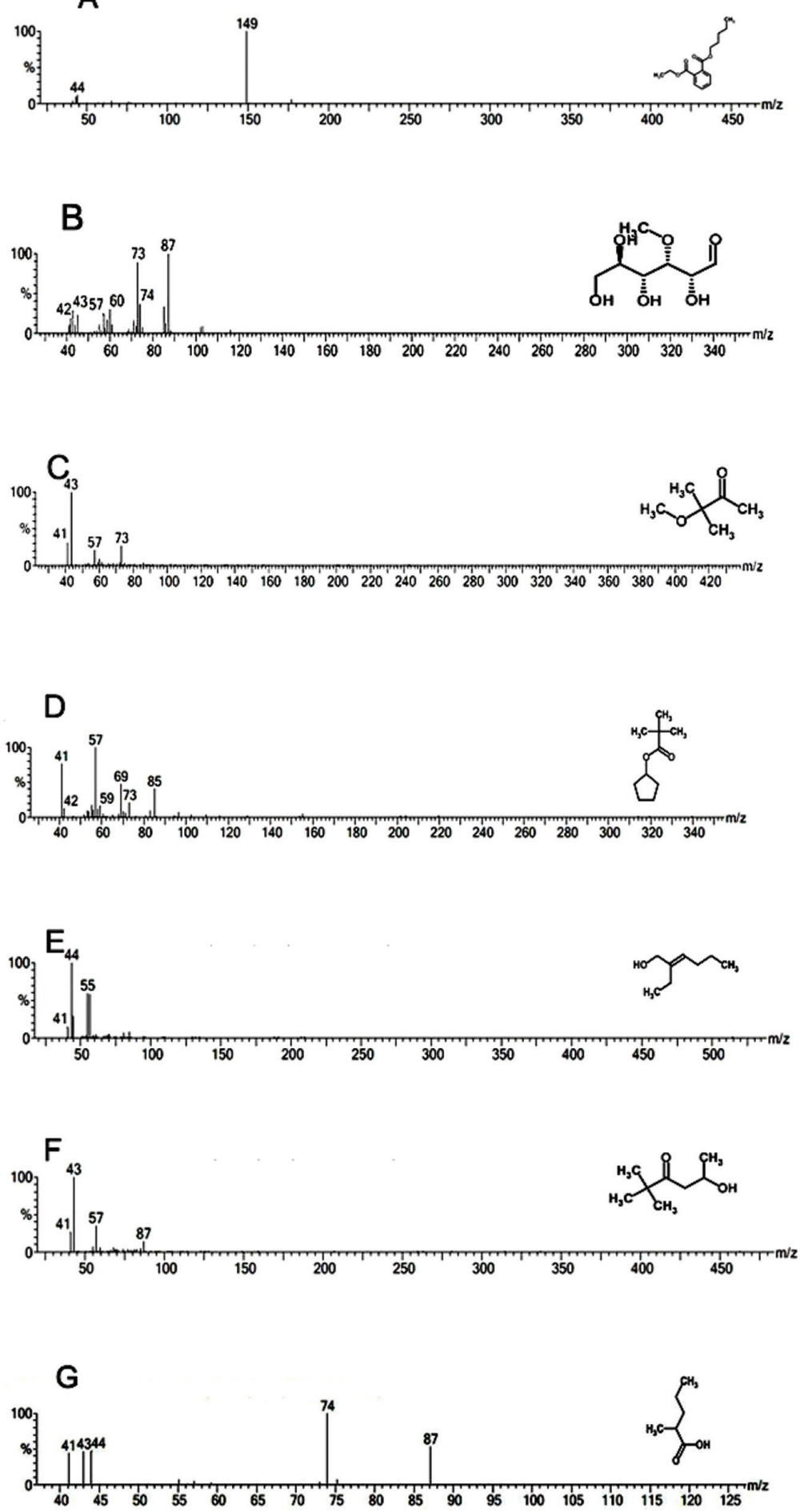

H

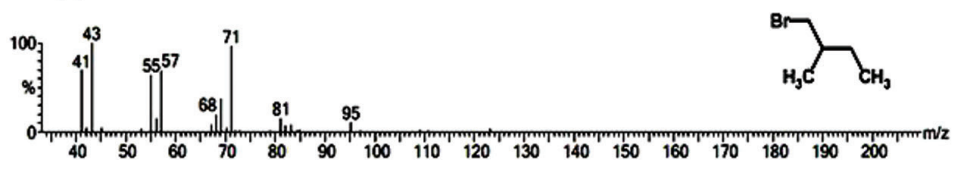

Figure 2: Mass spectra of 8 compounds, identified from methanol extract of $A$. caroliniana with structures as individual inserts, (A) phthalic acid, ethyl pentyl ester, (B) 3-0-methyl-d-glucose, (C) 2-butanone, 3-methoxy-3-methyl (D) 2,2-dimethylpropionic acid, cyclopentyl ester, (E) 2-hexen-1-ol, 2-ethyl, (F) 5-hydroxy-2,2-dimethylhexan-3-one, (G) pentanoic acid, 2-methyl, (H) butane, 1-bromo-2-methyl. 


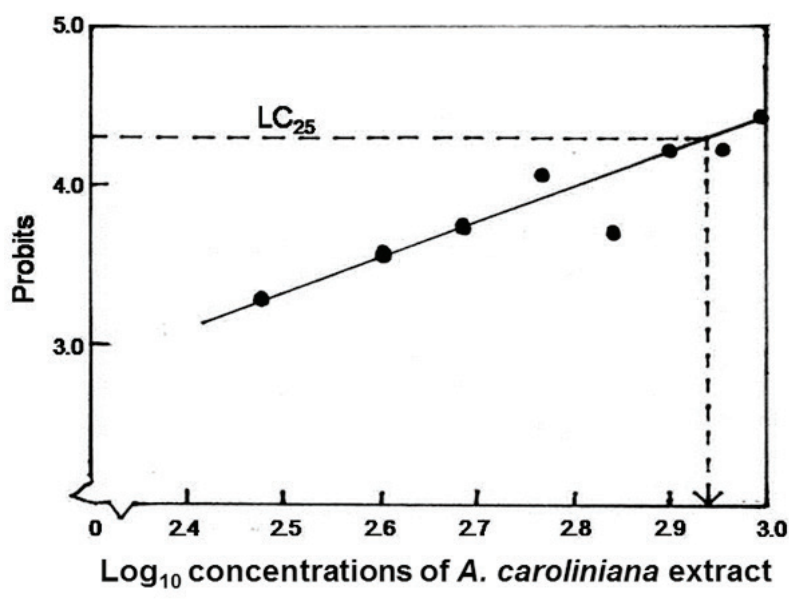

Figure 3: A plot of probits of lethal percent values against $\log _{10}$ concentrations of methanol extract of $A$. caroliniana in the cell toxicity during growth of lymphocytes with the graded levels of the extract assessed by TB staining method; the plot was used for the determination of extract concentrations for $\mathrm{LC}_{25}$ level of toxicity.

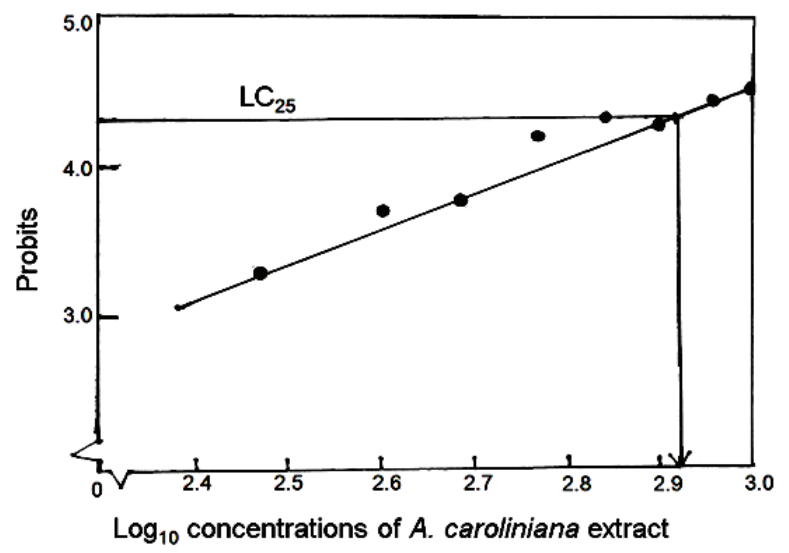

Figure 4: A plot of probits of lethal percent values against $\log _{10}$ concentrations of methanol extract of $A$. caroliniana in the cell toxicity during growth of lymphocytes with the graded levels of the extract assessed by AO/EB staining method; the plot was used for the determination of extract concentrations for $\mathrm{LC}_{25}$ level of toxicity.

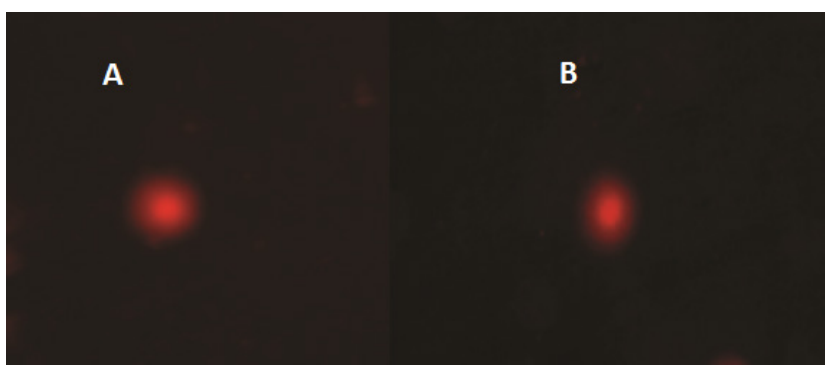

Figure 5: Comets to assess nuclear toxicity by the fern extract, (A) Control cells, (B) Cells had no comets when grown with $1000 \mathrm{mg} / \mathrm{l}$ of $A$. caroliniana extract. this $\log _{10}$ concentration value was the $\mathrm{LC}_{25}$ value, 870.96 $\mathrm{mg} / \mathrm{L}$ A. caroliniana extract (Figure 3).

Growth of lymphocytes with varying levels of $A$. caroliniana extract for $24 \mathrm{~h}$ showed the MIC at $300 \mathrm{mg} / \mathrm{L}$ extract. Probit values after $\mathrm{AO} / \mathrm{EB}$ staining (Table 2) were used in the ordinate and $\log _{10}$ values of $A$. caroliniana extract concentrations in the abscissa for the construction of the probit plot, from which it was ascertained that the $\mathrm{LC}_{25}$ value was $691.83 \mathrm{mg} / \mathrm{L}$ extract in this method (Figure 4).

Single cell gel electrophoresis was carried out to study DNA damage of the cells grown with different concentrations of $A$. caroliniana extract. It was observed that, comet was not found in the cells cultured with 0 to 1000 $\mathrm{mg} / \mathrm{L}$ extract (Figure 5).

The $\mathrm{LC}_{25}$ value was $870.96 \mathrm{mg} / \mathrm{L}$ A. caroliniana methanolic extract in the TB staining method, while the $\mathrm{LC}_{25}$ value was $691.83 \mathrm{mg} / \mathrm{L}$ extract in the $\mathrm{AO} / \mathrm{EB}$ staining method. But experimentally, the MIC value was $300 \mathrm{mg} / \mathrm{L}$ extract. $\mathrm{LC}_{25}$ is the concentration where $25 \%$ cell death occurs. Herein, MIC was far less than any of the two $\mathrm{LC}_{25}$ values in staining methods obtained by computation for cell death. Thus, the extract had no cellular toxicity, for the reason that $\mathrm{LC}_{25}$ value is higher than the MIC value. Since, no comet was found due to the extract, the nuclear toxicity was not too induced by it.

\section{DISCUSSION}

In the previous study, the solvent extracts of $A$. caroliniana were recorded having antibacterial activity against seven MDR pathogenic bacteria, among which most Gramnegative and Gram-positive bacteria were highly resistant to 17 currently used antibiotics. ${ }^{5}$ The methanol extract of $A$. caroliniana was recorded the best antibacterial activity against $S$. aureus in vitro, controlling the bacterial lawn at a MIC value of the methanolic extract, $1.89 \mathrm{mg} / \mathrm{mL}$; the highest concentration required for the total control any of $7 \mathrm{MDR}$ bacterium was $21.67 \mathrm{mg} / \mathrm{mL}$ methanolic extract as the minimum bactericidal concentration value. ${ }^{5}$ Thus, both antioxidant and antibacterial efficacies of the fern were elucidates. This work on chemical profiling of the fern as well as, toxicity analysis with umbilical cord blood lymphocytes adds to the confidence that this could be further cultivated aesthetically for use as supplementary food, and the Chinese uses as food is justified. There were 6 other minor phytochemicals. Synergistically, all phytochemicals should be contributing to the recorded antioxidant and antibacterial activity of $A$. caroliniana. Herein, it is recorded that even the value of $300 \mathrm{mg} / \mathrm{mL}$ methanolic extract of A. caroliniana is nontoxic to human lymphocyte cultures. 
Thus it could be suggested for the use of $A$. caroliniana as CAM during treatment if infection along with main stream medicines, i.e., antibiotics and other antibacterials. Additionally, the ability of the fern to produce an array of secondary metabolites, like several higher plants ${ }^{13-16}$ is considered important for the use against bacterial pathogens as a non-microbial antimicrobial agent against the array of bacterial self defense mechanisms, i.e., shenanigans in achieving resistance over applied antibacterials ${ }^{17}$ since the symbiotic fern has a higher litany of chemicals that could never be won upon by any prokaryote, equipped with armamentaria of multiresistance ${ }^{18}$ The present finding of the absence of hosttoxicity similar to the medicinal plants, Woodfordia fruticosa ${ }^{13}$ and Combretum albidum ${ }^{16}$ with human lymphocyte culture supported the use of the fern as complementary and alternative medicine (CAM), along with mainstream antibiotics. The concept of CAM of using phyto-drugs is now widely held, being promoted by World Health Organization $^{19}$, and in the future it would become deeply held for failure of main stream medicine for several grimmish ailments. In the developed world too, the use of phyto-drugs as CAM is the new emerging social paradigm. ${ }^{19}$

In the previous report, the presence of flavonoids in alcoholic extracts of the species was the probable causative agents for the recorded antioxidant activity, ${ }^{5}$ as known with higher plants. ${ }^{20} \mathrm{Furthermore}$, the presence of phenols in all 4 solvent extracts of $A$. caroliniana was reported, ${ }^{5}$ and the phenolic acid is known to be responsible for the antimicrobial activity of higher and lower plants. ${ }^{21}$

OMG is a nontoxic, non-metabolizable glucose analogue, effective in reducing the toxicity of streptozotocin (causative natural chemical of cancer development in islets of langerhans of pancreas in human); 3-o-methyld-glucose or OMG has been reported to possess antitumor properties.22 Additionally, OMG has several biologic actions, and the most leading one is that this sugar is rapidly taken up by insulinoma cells (benign tumour cells of pancreas, in patients with hypoglycemia) (https://www.wikigenes. org/e/chem/e/298225. html). As OMG is amply present in $A$. caroliniana, a vivid research with animal models for its possible use as CAM for people suffering from malfunction of secreted insulin, resulting in frequent hypoglycemia, who often have insulinoma cells. Such a high percentage, 91.89\% of OMG in $A$. caroliniana qualifies the plant aptly as a potent antioxidant too. Eventually, further work with chemicals of the species, if done with finesse could open up a field of locating/aiding to anticancer drugs.
Likewise, another compound located in A. caroliniana, 'phthalic acid, ethyl pentyl ester' is a derivative of phthalic acid, an aromatic compound, reported being too isolated from the medicinal plant, Leea indica (Burm. F) Merr flowers with esters of phthalic acid at $95.6 \%$ had remarkable antibacterial and antifungal activities. ${ }^{23}$ Thus, the reported antibacterial efficacy of $A$. caroliniana, even against MDR pathogenic bacteria ${ }^{5}$ could be related to the presence of this chemical. However, the remaining 6 phytochemicals seen in this GC-MS analysis could contribute to antioxidant/antimicrobial potencies of the fern. Despite, the bioactivities of these compounds isolated from other plants are not reported yet, as searched systematically in databases, all phytochemicals together have a natural synergistic action, as reported for an Indian herbal formulation. ${ }^{24}$ To sum up, it could be stated that Azolla sp. would more suitable as a natural source of antioxidants than as a source of antimicrobials, for the presence of OMG, apart from several other phytochemicals. When this could be verified with in vivo experiment models, a prominent business tycoon could be initiated with Azolla sp.

\section{CONCLUSION}

It was evident in the present study that only one phytochemical, 3-o-methyl-d-glucose with RT $16.581 \mathrm{~min}$ and a peak area of $91.89 \%$ was present largely in A. carolinianaa and it is a glucose analogue along with its well proven antioxidant activity, it could be taken as a food grade palnt. Additionally, the second most prevalent chemical, 'phthalic acid, ethyl pentyl ester' has remarkable antibacterial properties. Thus the plant extract has double beneficial effects antioxidant and antibacterial activates. There were 6 other minor phytochemicals, which synergistically contribute to the major activity of $A$. caroliniana. Its methanolic extract had neither cellular nor nuclear toxicity with cultured human lymphocytes. If it could be grown aesthetically, Azolla sp. could be taken as safe, food grade plant.

\section{ACKNOWLEDGEMENT}

This work is a part of $\mathrm{PhD}$ thesis of $\mathrm{N}$. Nayak in Biotechnology, who is supported by a fellowship from Siksha 'O' Anusandhan University and a project from Council of Scientific and Industrial Research, New Delhi (grant no. 21 (0859)/11/EMR-II), awarded to RN Padhy. Thank are due to Dr. Sujit K. Nayak, Senior Technician, DWRDA, Bhubaneswar for helping in Azolla growth. RN Padhy is an Emeritus Scientist from Council of Scientific and Industrial Research, New Delhi. Prof. Dr. MR Nayak, President, Siksha 'O' 
Anusandhan University, Bhubaneswar provided extended facilities.

\section{CONFLICT OF INTEREST}

The authors have no conflict interest.

\section{ABBREVIATIONS USED}

AO/EB: Acridine orange/ethidium bromide; CAM: Complementary and alternative medicine; DMEM: Dulbecco's modified Eagle's medium; DMSO: Dimethyl sulfoxide; FBS: Fetal bovine serum; GC-MS: Gas chromatography and mass spectrometry; LC: Lethal concentration; LMPA: Low melting point agarose; LSM: Lymphocyte separating medium; MDR: Multidrug resistant; MIC: Minimum inhibitory concentration; OMG: 3-o-methyld-glucose; RT: Retention time; PBS: Phosphate buffered saline; RBC: Red blood cells; TB: Trypan blue; UCB: Umbilical cord blood.

\section{REFERENCES}

1. Singh PK. Use of Azolla in Asian agriculture. Appl Agri Res. 1989;4:149-61.

2. Arora A, Singh PK. Comparison of biomass productivity and nitrogen fixing potential of Azolla spp. Biomass Bioenergy. 2003;24(3):175-8. https://doi. org/10.1016/S0961-9534(02)00133-2.

3. Yadav RK, Abraham G, Singh YV, Singh PK. Advancements in the utilization of Azolla-Anabaena system in relation to sustainable agricultural practices. Proc Indian Natn Sci Acad. 2014;80(2):301-16. https://doi.org/10.16943/ ptinsa/2014/v80i2/55108.

4. Xiaofeng L, Chen M, Liu X, Liu C. Research on some functions of Azolla in CELSS system. Acta Astronautica. 2008;63(7):1061-6.

5. Nayak N, Padhy RN, Singh PK. Evaluation of antibacterial and antioxidant efficacy of the fern Azolla caroliniana symbiotic with the cyanobacterium Anabaena azollae. PNAS India; Sec B, Biol Sci. 2014; 85(2):555-69. https:// doi.org/10.1007/s40011-014-0370-3.

6. Teixeiraa G, Carrapicob F, Gomez ET. C-glycosyl flavones in the genus Azolla. Plant Biosystem. 2001;135(2):233-7. https://doi.org/10.1080/112635 00112331350870 .

7. Mithraja MJ, Antonisamy JM, Mahesh M, Paul ZM, Jeeva S. Phytochemical studies on Azolla pinnata R. Br., Marsilea minuta L. and Salvinia molesta Mitch. Asian Pacif J Trop Biomed. 2011;1(1):S26-9. https://doi.org/10.1016/ S2221-1691(11)60116-0.
8. Abraham G, Aeri V. A preliminary examination of the phytochemical profile of Azolla microphylla with respect to Seasons. Asian Pacif J Trop Biomed. 2012;2(3):S1392-5. https://doi.org/10.1016/S2221-1691(12)60423-7.

9. Selvaraj K, Chowdhury R, Bhattacharjee C. Isolation and structural elucidation of flavonoids from aquatic fern Azolla microphylla and evaluation of free radical scavenging activit. Int J Pharmacy Pharma Sci. 2013;5(3):743-9.

10. Abraham G, Yadav RK, Kaushik GK. Antimicrobial activity and identification of potential antimicrobial compounds from aquatic pteridophyte, Azolla microphylla Kaulf. Indian J Exp Biol. 2015;53(4):232-5. PMid:26011985.

11. Patnaik R, Padhy RN. Cellular and nuclear toxicity of $\mathrm{HgCl} 2$ to in vitro grown lymphocytes from human umbilical cord blood. PNAS India; Sec B, Biol Sci. 2015;85(3):821-30. https://doi.org/10.1007/s40011-015-0503-3.

12. Subudhi BPR, Singh PK. Nutritive value of water fern Azolla pinnata for chicks. Poultry Sci. 1978; 57(2): 378-80. https://doi.org/10.3382/ps.0570378.

13. Dubey D, Patnaik R, Ghosh G, Padhy RN. In vitro antibacterial activity, gas chromatography-mass spectrometry analysis of Woodfordia fruticosa Kurz. leaf extract and host toxicity testing with in vitro cultured lymphocytes from human umbilical cord blood. Osong Public Health Res Perspect. 2014;5(5):298-312. https://doi.org/10.1016/j.phrp.2014.08.001; PMid:25389517 PMCid:PMC4225590

14. McLafferly FW. Registry of mass spectral data. fifth ed. New York: John Wiley and Sons; 1989.

15. Tice RR, Agurell E, Anderson D, Burlinson B, Hartmann A, Kobayashi H, et al. Single cell gel/ comet assay: guidelines for in vitro and in vivo genetic toxicology testing. Environ Mol Mutagenesis. 2000;35(3):206-21. https://doi. org/10.1002/(SICI)1098-2280(2000)35:3<206::AID-EM8>3.0.CO;2-J.

16. Sahu MC, Patnaik R, Padhy RN. In vitro combination-efficacy of ceftriaxone and leaf-extract of Combretum albidum $\mathrm{G}$. Don against multidrug resistant Pseudomonas aeruginosa and host-toxicity testing with lymphocytes from human cord blood. J Acute Med. 2014; 4(1): 26-37. https://doi.org/10.1016/j. jacme.2014.01.004.

17. WHO. The burden of health care-associated infection worldwide. Available at, http://www.who.int/gpsc/country_work/summary_20100430_en.pdf. 2011.

18. Canton R, Morosini MI. Emergence and spread of antibiotic resistance following exposure to antibiotics. FEMS Microbiol Rev. 2011;35(5): 977e991.

19. Ernst E. Prevalence of use of complementary/alternative medicine: a systematic review. Bull. World Healt Organ. 2000;78(2):258-66.

20. Pietta PG. Flavonoids as antioxidants. J Nat Prod. 2000;63(7):1035-42. https://doi.org/10.1021/np9904509; PMid:10924197.

21. Nitiema LW, Savadogo A, Simpore J, Dianou D, Traore AS. In vitro antimicrobial activity of some phenolic compounds (coumarin and quercetin) against gastroenteritis bacterial strains. Int J Microbiol Res. 2012;3(3):183-7.

22. Wick MM, Rossini A, Glynn D, Leukemia with enhancement of antitumor activity in murine 11210 reduction of streptozotocin toxicity by 3-o-methyl-dglucose. Cancer Res. 1977;37(11):3901-3. PMid:198124

23. Srinivasan GV, Sharanappa P, Leela NK, Sadashiva CT, Vijayan KK. Chemical composition and antimicrobial activity of Leea indica (Burm. F) Merr flowers. Natl Prod Rad. 2009;8(5):488-93.

24. Dhawan K, Kumar SK, Sharma A. Comparative anoxilytic activity profile of various preparations of Passiflora incarnata L.: a comment of medicinal plants' standardization. J Alter Comp Med. 2002;8(3):283-91. https://doi. org/10.1089/10755530260127970; PMid:12165186.

\section{SUMMARY}

- Azolla caroliniana, the water fern, symbiotic with the N2-fixing cyanobacterium, Anabaena azollae is traditionally used as a bio-fertilizer in Asian rice farming, and an animal fodder as well as, occasionally as human food.

- The GC-MS analysis of the methanol extract of $A$. caroliniana was carried and in vitro host-toxicity testing was carried out with cultured lymphocytes from human umbilical cord blood.

- From the GC-MS analysis total 8 phytochemicals were identified, and 3-O-methyl-d-glucose was the major phytochemical with a peak area of $91.89 \%$.

- During host toxicity testing, methanol extract had neither cellular nor nuclear toxicity to cultured human lymphocytes.

- If it could be grown aesthetically, A. caroliniana could be taken as safe, food grade plant. 


\section{About Authors}

Nabakishore Nayak, M.Sc.: He is pursuing Ph. D. in Biotechnology at Central Research Laboratory, IMS \& Sum Hospital, Siksha 'O' Anusandhan University, Bhubaneswar 751003, Odisha, India, with a full-time university fellowship. His research interests include isolation and identification of bioactive secondary metabolites from plants and cyanobacteria as well as, pharmaco-toxicological studies on phyto-constituents. He has published several papers on antioxidants and nosocomial infections, apart from of publications on cyanobacteria and rice farming. Email: nkishorenayak@ yahoo.co.in

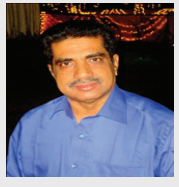

Rabindra N. Padhy, Ph.D., MNAMS: Now is working as Research Professor, IMS \& Sum Hospital, Siksha 'O' Anusandhan University, Bhubaneswar, Odisha. Research Areas: Microbiology, Medicinal plants, Phyto-chemistry, Environmental Sciences, Genetics; he was awarded, CSIR Emeritus Scientist, Samanta Chandra Shekhar Award, Outstanding young person. He has outstanding contributions in agricultural and medical sciences.

Cite this article: Nayak N, Padhy RN. GC-MS analysis of bioactive compounds and host-toxicity studies of $A$ zolla caroliniana symbiotic with the cyanobacterium Anabaena azollae. Indian J of Pharmaceutical Education and Research. 2017;51(2S):S24-S33. 